\title{
EDITORIAL
}

\section{Continuity and change}

\author{
HP Rang and JC McGrath
}

\section{A message from the retiring Editor}

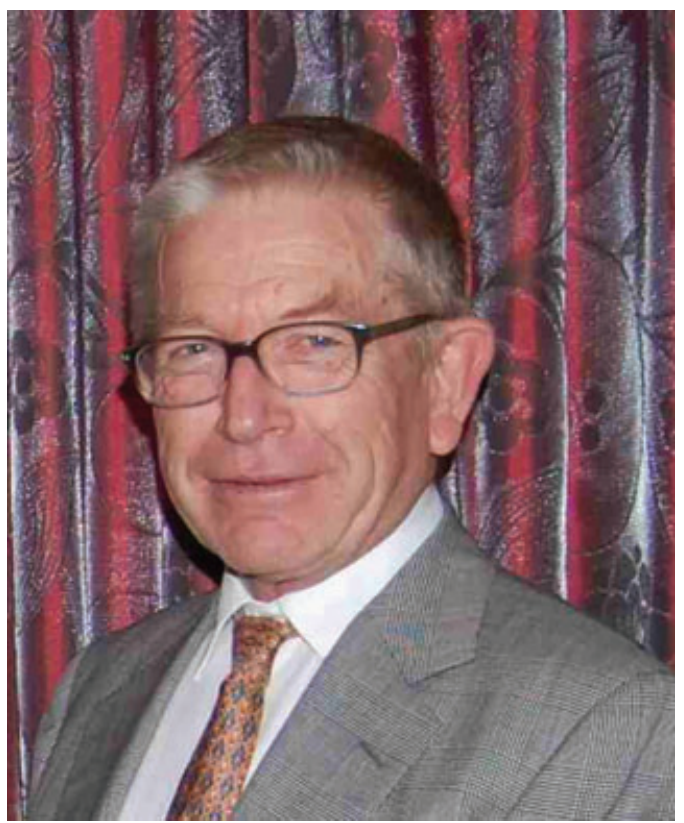

This issue of BJP marks the end of an eventful year and the beginning of the next phase in the journal's development under its new Editor-in-Chief and its new publishers, WileyBlackwell.

Why change publishers, when Nature Publishing Group (previously Macmillan Journals) has served the journal well since 1968? Much has changed in the world of journal publishing since then, and as the end of the NPG contract was imminent, the British Pharmacological Society decided in 2008 to look afresh at what different publishers had to offer. A working party reviewed proposals from several well-known publishers - all of them keen to take on the BPS journals - and after much deliberation, settled on Wiley-Blackwell, the current publisher of the British Journal of Clinical Pharmacology $(B J C P)$, building on our long-standing partnership with them on BJCP. Financially, the society will fare considerably better than before, with a guaranteed income that provides security in hard economic times. Most importantly, BJP and BJCP will be able to work together, so as to cover the whole span of pharmacology in a coherent and planned way that has been difficult hitherto.
Passing this milestone gives a chance for the retiring editor to reflect on what has changed since 2005, and for the new editor to share his thoughts as he faces the task ahead.

Taking over from Alan North in 2005 was easy, because he had set up a very smooth-running and efficient editorial system, supported by Anna Muir and her team at the BPS offices in London, leaving me free to focus on the content and quality of BJP. One of my first tasks, a very enjoyable one, was to put together a special issue commemorating the $75^{\text {th }}$ anniversary of BPS and the $60^{\text {th }}$ of $B J P$, by commissioning a series of articles on notable discoveries involving British pharmacologists, written by those who had been closely involved, starting with a brief history of the BPS (Cuthbert, 2006) and culminating with a look to the future (Vallance \& Smart, 2006). The authors entered fully into the spirit of the thing and came up with an informative and entertaining collection that has proved very popular and highly cited. Another ongoing success is the Guide to Receptors and Channels (GRAC), a much-valued and regularly updated compendium that is published as a BJP supplement (Alexander et al., 2008). The drive and hard work comes, of course, from its editors; all the editor-in-chief has to do is give encouragement to this enterprise, which brings so much credit to the journal.

In 2005 BJP was evidently in good health, and well respected by the pharmacological research community, so what should a new editor try to do, apart from keeping things on course? I felt that it was becoming too narrow in its scope, focusing very heavily on 3 areas of pharmacology - cardiovascular, inflammation and neuropharmacology - with too few papers on other important, and growing areas, such as cancer, infectious diseases, molecular pharmacology, endocrine and metabolic pharmacology, pharmacokinetics and drug metabolism. Such specialisation tends to be selfreinforcing, so active measures were needed to restore the proper scope of the subject. With this in mind, we embarked on a much more aggressive campaign to commission highquality review articles covering topics outside our mainstream ones, and we also introduced, for the first time, special themed issues and themed sections, under specialist Guest Editors (Alexander and Randall, 2007; Mackie and Ross, 2008; Lawrence et al., 2008; McGrath and Cowan, 2008; Pugsley et al., 2008). These initiatives have gone very well. The new reviews sub-committee, under Dr M J Curtis, is generating a regular stream of excellent reviews on a wide range of topics, that are popular with readers and highly cited. The themed issues, now a regular feature, likewise are being used 
successfully to focus attention on growth areas. These changes have given BJP a new look and a new feel, and brought it to the attention of researchers who may not see themselves as pharmacologists even though drugs and drug action are the focus of their work; they are surely a good thing for that reason alone. It is too soon to judge whether they are having the desired effect of expanding the scope of submitted research papers, but we have been pleased by the sharp increase in total submissions to BJP. During 2004-6, submissions had shown a gradual worrying decline and $B J P$ had been getting thinner. In 2007 submissions jumped by about $9 \%$, and in 2008 by more than $20 \%$, with the result that the journal will exceed its planned allowance of 5000 pages for the first time in living memory. Submissions are the life-blood of any journal, so this is very good news.

In 2006, with NPG's help, we also gave the journal a new look with a design makeover, which was certainly an improvement. Abstracts play an important part in a reader's decision to read the paper in full, so we introduced a new structured format for abstracts to ensure that they covered the relevant details succinctly and, most importantly, made clear the implications of the work. We also appointed Dr Mick Bakhle as an expert Press Editor, to vet accepted papers for clarity, style and terminological consistency. His attention to detail has brought about a big improvement. In addition, BJP became the only biomedical journal to offer free language editing. We are lucky in the UK that the international language of science is also our native language, and we surely have a duty to help scientists from overseas to overcome the language barrier.

No journal editor these days can afford to ignore Impact Factors. Notwithstanding all the valid criticisms that have been heaped on this invidious metric, it remains a major determinant of where authors choose to publish their best work. BJP's Impact Factor hovered around 3.5 for several years, before improving to 3.8 in 2006 and remaining there in 2007. The more recent citation figures that will govern the 2008 IF show an encouraging upward trend, with review articles (which are more highly cited on average than research papers) making a substantial contribution, so we expect to pass the important threshold of 4 in 2008, no doubt before going even higher.

For me, the excitement of pharmacology has always been its role as the main driver of therapeutic advances, which gives it a unique status among the biomedical sciences. What other discipline takes us all the way from the genome to the bathroom cabinet? However, its critical relationship with medicine is sometimes neglected, allowing a cultural divide to develop between the basic and clinical parts of what should be one powerful discipline. For the BPS to appoint separate publishers for $B J P$ and $B J C P$ was surely a mistake. We should rejoice in the fact that it has now been corrected, allowing the journals to work together to cover the full range of pharmacology without commercial barriers.

The last few months have been devoted to making all the technical arrangements for transferring BJP from Nature Publishing Group to Wiley-Blackwell, a task now complete in a way that we expect to produce little or no disruption for authors or subscribers. The next task, for my successor, Professor Ian McGrath, in collaboration with the BJCP Editor-in-
Chief, Professor Jim Ritter, and the Wiley-Blackwell team, will be to make plans that will exploit the full potential of the new relationships.

My 4-year stint as editor-in-Chief has been challenging and enjoyable and the years have gone quickly. I have appreciated enormously the support of the BPS journal team - Anna Muir, Hazel O'Mullan and Paul Tizard - whose willingness, experience and good humour have kept me (more or less) out of trouble. In some ways I am sorry to be handing over at such an exciting time for the journal, but I am happy with what has been achieved and confident that Ian McGrath will take $B J P$ from strength to further strength.

\section{A message from the new Editor}

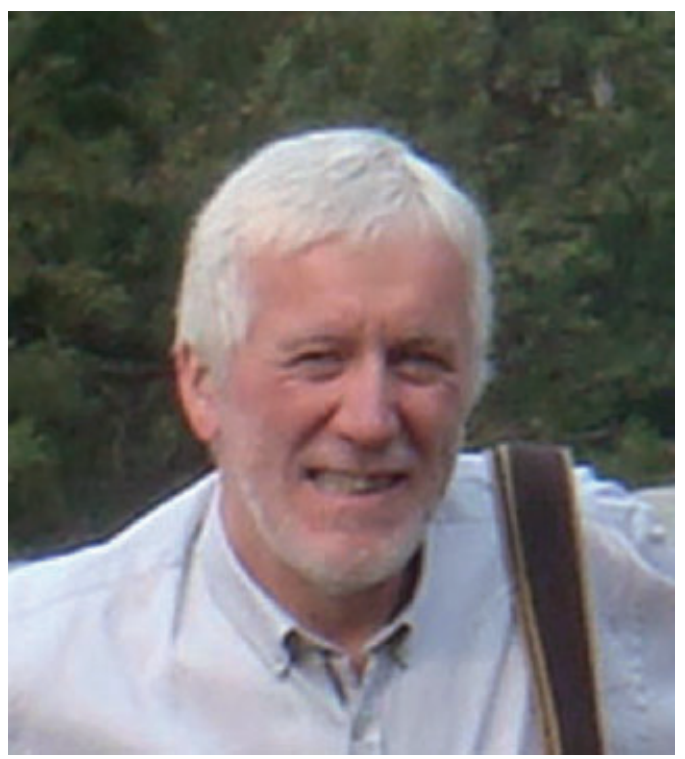

This is an interesting time to be setting out to lead the $B J P$ team and to carry on Humphrey Rang's excellent stewardship. We now have the same publisher for BJP and BJCP, Wiley-Blackwell, supplying new energy, ideas and a strong presence across all fields of pharmaceutical and medical research. This means that the two journals can work together to cover the whole of pharmacology. Each journal has been seen as covering a narrower spectrum of pharmacology than we intend and we can now broaden this. We can also make more use of editorial content, drawing on expertise from across the whole spectrum. The intention is both to expand the reach of our publications across the whole field of understanding drugs and to provide a real showcase for pharmacology.

The editorial teams on $B J P$ and $B J C P$ are fully committed to these goals and the publishers are geared up to employ innovative approaches to facilitate this, such as compiling joint tables of contents as "virtual themed issues" that can cover both journals. Pushing the translational agenda, "Bench to Bedside", will become much easier. The thematic concept and the increased use of reviews that we have developed in the last 
couple of years will be used to the full, and will provide an attractive publication platform for related original papers. It will also allow better integration with the BPS and other meetings programmes.

This issue of $B J P$ represents the success of a seamless transition to publication by Wiley-Blackwell. There will now follow a number of innovations in the course of 2009, but a sneak preview, and one close to my own heart, will be the free availability of full colour, which, I believe, will prove a boon and an incentive to publish in BJP for those of us using imaging and other visual technologies.

However, the journal's success depends only partly on what our team does. It will mainly depend on our authors submitting their best work across the whole field. Our job is to encourage them to do that.

A troublesome issue is that many of us submit our best papers to either non-specialist general journals, or to narrow specialist journals, with high impact factors. This arises because many in authority, who know little about academic publishing, judge us by this criterion. This is, of course, irrational because the important point about citations or other usage statistics is how many times our own article is cited or read over its life, be it one year or twenty, not the average for the journal in the two calendar years after publication year (the basis of the commonly used impact factor). It looks as if the use of this particular "output measure" may be shifting because, as governments of countries and universities move towards metric-based assessment (e.g. in UK, Australia), they are realising that the actual piece of work is the important thing. For example, they are now looking at such measures as the "H-index", which evaluates the individual scientist by the citations of their work. Of course there will always remain an element of kudos in the journals in which the articles appear. In this respect, $B J P$ retains a reputation for high standards that we should be proud of.

So we are doing all we can to ensure that $B J P$, with $B J C P$, evolves into the leading international platform for publication in pharmacology. Please join us in this by sending us manuscripts of your best work on any aspect of drug research.

\section{References}

Alexander, S.P.H. Mathie, A. \& Peters, J.A. (2008). Guide to receptors and channels (GRAC), 3rd edition. Br J Pharmacol, 153 (Suppl. 2), S1-S209.

Alexander, S.P.H. \& Randall, M. (2007). Cannabinoids and their actions. Br J Pharmacol 152, 557-558.

Cuthbert, A.W. (2006) A brief history of the British Pharmacological Society. Br J Pharmacol 147, S2-S8.

Lawrence, A.J. Beart, P.M. \& Kalivas, P.W. (2008). Neuropharmacology of addiction-setting the scene. Br J Pharmacol 154, 259-260.

Mackie, K. \& Ross R.A. (2008). CB2 cannabinoid receptors: new vistas. Br J Pharmacol 153, 177-178.

McGrath, J.C. \& Cowan, D.A. (2008). Drugs in sport. Br J Pharmacol 154, 493-495.

Pugsley, M.K. Authier, S. \& Curtis, M.J. (2008). Principles of safety pharmacology. Br J Pharmacol 154, 1382-1399.

Vallance, P. \& Smart, T G. (2006). The future of pharmacology. $\mathrm{Br} J$ Pharmacol 147, S304-S307. 